\title{
Impaired Left Atrial Function in Heart Failure with Preserved Ejection Fraction
}

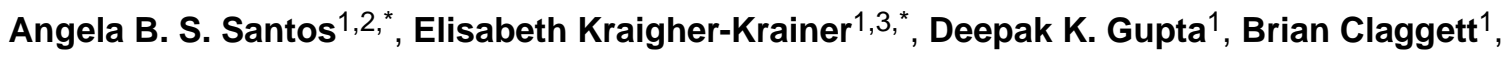 \\ Michael R. Zile ${ }^{4}$, Burkert Pieske ${ }^{3}$, Adriaan A. Voors ${ }^{5}$, Marty Lefkowitz ${ }^{6}$, Toni Bransford ${ }^{6}$, \\ Victor Shi ${ }^{6}$, Milton Packer ${ }^{7}$, John J. V. McMurray ${ }^{8}$, Amil M. Shah ${ }^{1}$, Scott D. Solomon ${ }^{1}$, and \\ for the PARAMOUNT Investigators \\ ${ }^{1}$ Cardiovascular Division, Brigham and Women's Hospital, Boston, MA, USA ${ }^{2}$ Postgraduate \\ Program in Cardiovascular Sciences, Cardiology, Federal University of Rio Grande do Sul, BR \\ ${ }^{3}$ Medical University Graz, Graz, Austria ${ }^{4} \mathrm{RHJ}$ Department of Veterans Affairs Medical Center and \\ Medical University of South Carolina, Charleston, SC, USA ${ }^{5}$ University of Groningen, Groningen, \\ The Netherlands ${ }^{6}$ Novartis Pharmaceuticals, East Hanover, NJ, USA ${ }^{7}$ University of Texas \\ Southwestern, Dallas, TX, USA ${ }^{8}$ University of Glasgow, Glasgow, UK
}

\begin{abstract}
Aims-Left atrial (LA) enlargement is present in the majority of heart failure with preserved ejection fraction (HFpEF) patients and is a marker of risk. However, the importance of LA function in HFpEF is less well understood.
\end{abstract}

Methods and Results-The PARAMOUNT trial enrolled HFpEF patients (LVEF $\geq 45 \%$, NTproBNP $>400 \mathrm{pg} / \mathrm{ml}$ ). We assessed LA reservoir, conduit and pump function using $2 \mathrm{D}$ volume indices and speckle tracking echocardiography in $135 \mathrm{HFpEF}$ patients in sinus rhythm at the time of echocardiography and 40 healthy controls of similar age and gender. LA strain was related to clinical characteristics and measures of cardiac structure and function. Compared to controls, HFpEF patients had worse LA reservoir, conduit, and pump function. The differences in systolic LA strain (Controls, $39.2 \pm 6.6 \%$ vs HFpEF, $24.6 \pm 7.3 \%$ ) between groups remained significant after adjustments and even in the subsets of HFpEF patients with normal LA size or without a history of AF. Among HFpEF patients, lower LA strain was associated with higher prevalence of prior HF hospitalization and history of AF, as well as worse LV systolic function, higher LV mass and LA volume. However, NT-proBNP and E/E' were similar across the quartiles of LA function.

Conclusions-In this HFpEF cohort, we observed impairment in all phases of LA function, and LA strain was decreased independent of LA size or history of AF. LA dysfunction may be a marker of severity and play a pathophysiologic role in HFpEF.

Clinical Trial Registration-(Clinicaltrials.gov NCT00887588)

Correspondence to Scott D. Solomon, MD, Cardiovascular Division, Brigham and Women's Hospital; 75 Francis St, Boston, MA 02445; Tel: 857-307-1960/ Fax: 857-307-1944; ssolomon@ rics.bwh.harvard.edu.

Both authors contributed equally to this article.

Conflict of interest: Drs. MRZ, BP, AAV, MP, JJVM, AMS and SDS have received research support and have consulted for Novartis. Drs. ML, TB and VS are employees of Novartis. Drs. ABSS, EKK, DKG and BC declare that they have no conflict of interest. 


\section{Keywords}

Diastolic Heart Failure; Echocardiography; Atrial Strain

\section{Introduction}

Heart failure with preserved ejection fraction (HFpEF) is common, ${ }^{1,2}$ particularly among elderly, female, and hypertensive patients, and is frequently associated with atrial fibrillation. ${ }^{3,4}$ This condition is also associated with increased mortality and hospital readmission. ${ }^{5,6}$ The pathophysiologic mechanisms underlying HFpEF are heterogeneous and incompletely understood. Traditionally, HFpEF has been attributed to abnormal left ventricular (LV) diastolic function, including abnormalities in active relaxation and passive stiffness. ${ }^{7,8}$ Left atrial (LA) enlargement is a recognized marker for LV diastolic function and is independently associated with an increased risk for morbidity and mortality. ${ }^{9-11}$ While increased LA size is present in the majority of HFpEF patients, approximately onethird do not have LA enlargement. ${ }^{10,12}$ The role of all 3 phases of LA function in HFpEF patients is less well understood, ${ }^{13,14}$ particularly in those without a history of atrial fibrillation (AF) and with normal LA size.

We used baseline data from the The Prospective comparison of ARNI with ARB on Management Of heart failUre with preserved ejectioN fraction (PARAMOUNT) Trial, a large well-phenotyped cohort of HFpEF patients, to test the hypothesis that LA function is abnormal in HFpEF patients, even among patients without LA enlargement or history of AF. We also sought to determine the clinical and echocardiographic correlates of reduced LA strain in patients with HFpEF.

\section{Methods}

\section{Study Population}

The PARAMOUNT trial (Clinicaltrials.gov NCT00887588) recruited patients between Nov, 2009 and March, 2011 and was undertaken in 65 centers and 13 countries. The trial enrolled men and women over 40 years of age, with LV ejection fraction (LVEF) $\geq 45 \%$, documented history of heart failure with NYHA class II-IV symptoms, and NT-proBNP levels $>400$ $\mathrm{pg} / \mathrm{mL}$ at the baseline visit. ${ }^{15}$ Patients were excluded if they had a previous LVEF less than $45 \%$ at any time, isolated right heart failure due to pulmonary diseases, dyspnea due to noncardiac causes such as pulmonary diseases, anemia or severe obesity, primary valvular, coronary or cerebrovascular disease. The number of patients enrolled with AF was limited to approximately $25 \%$ of the total sample, checked by ECG at screening. Of the 301 patients enrolled in the PARAMOUNT trial, 135 patients were in sinus rhythm (SR) at the time of echocardiography and had image quality sufficient for LA speckle tracking analysis (excluded patients: 75 in AF at the time of echocardiography; 47 non-DICOM images; 44 missing view(s) and/or unsuitable images for LA speckle tracking analysis). Among the 135 included patients, 32 self-reported a history of AF and/or were in AF according to the screening ECG (performed one week before the echocardiogram), but were in SR at the time of echocardiography. 
A group of 40 healthy controls was retrospectively identified from the medical records of the Brigham and Women's Hospital (BWH). The search strategy targeted patients $>55$ years who had an echocardiogram, and no ICD-9 code in their record for any of the following conditions: hypertension, ischemic heart disease, cardiac arrhythmia, hypercholesterolemia, chronic obstructive lung disease, diabetes mellitus, cerebrovascular disease, arterial vascular disease, and cancer. This group was further selected to have normal LVEF, no LV regional motion abnormalities, normally sized cardiac chambers, no significant valvular disease and suitable echocardiogram image quality. Controls were of a similar age and gender distribution to the HFpEF group. Our final control sample was achieved from an initial search including 2,000 patients. The study protocol was approved by the BWH Institutional Review Board.

\section{Echocardiographic Analyses}

Standard echocardiographic and Doppler parameters were analyzed using an offline analysis workstation at the Cardiovascular Imaging Core Lab at BWH, Boston, MA. All prespecified measurements in the PARAMOUNT trial were made in triplicate in accordance with the recommendations of the American Society of Echocardiography ${ }^{16,17}$ and included LA and LV diameter and volumes, LV wall thickness, LV mass, LVEF, mitral inflow propagation and lateral mitral annular relaxation velocities. LV stroke work (SW) was calculated as follows: $\mathrm{SW}=$ systolic blood pressure*stroke volume*0.014. ${ }^{18}$

LA and LV function indices were measured using B-mode speckle-tracking vendorindependent software with algorithms designed for the LV (TomTec Imaging Systems, Unterschleissheim, Germany) that is angle independent and identifies cardiac motion by tracking multiple reference points over time. ${ }^{19,20}$ The LA and LV endocardial borders were traced at the end-diastolic frame of 2D images acquired from the 12 segments using apical 2- and 4-chamber views. ${ }^{19}$ The PARAMOUNT echocardiography protocol required the proper alignment of apical views, in order to capture the LA in full, avoiding foreshortening of the chamber and to maintain a frame rate of 50-80 frames per second during the acquisition. End-diastole was defined by the QRS complex or as the frame after mitral valve closure. Speckles were tracked frame by frame throughout the LA and LV myocardium over the course of one cardiac cycle; basal, mid, and apical regions of interest were then created. Semi-quantitative segment tracking was carefully inspected for each image and manually adjusted as needed. If more than 2 segments could not be tracked or there was a lack of a full cardiac cycle or significant foreshortening of the cavity, the measurements were considered unreliable and the patient was excluded from the analysis. For LV function analysis, global longitudinal strain was calculated as the average LV longitudinal strain across the apical 4and 2-chamber views. ${ }^{21}$ From LA speckle tracking analysis, LA phasic function was estimated using volumes and strain indices calculated as the average across the apical 4- and 2-chamber views. LA volumes versus time curves were generated by calculating LA volume at each phase of the cardiac cycle (LA maximal, LA pre-A, and LA minimum volumes) using the biplane Simpson's method (Figure 1-left panel). From LA volumes, LA phasic function was estimated as:

- $\quad$ LA emptying fraction (reservoir function $)=[($ LA maximum volume - LA minimal volume)/LA maximum volume]*100. 
- $\quad$ LA passive emptying fraction (conduit function) $=[$ (LA maximum volume - LA pre- A volume)/LA maximum volume]*100

LA active emptying fraction (pump function $)=[($ LA pre-A volume - LA minimal volume)/LA pre-A volume]*100

Also LA reservoir function was estimated as LA expansion index (LA maximum volume LA minimal volume)/LA minimal volume]*100. From LA strain analysis, LA phasic function was estimated using: peak strain during systole (systolic LA strain) to assess reservoir function, early peak strain rate during diastole (LA passive strain rate) to assess conduit function, and late peak strain rate during diastole (LA active strain rate) to assess pump function (Figure 1-middle and right panel). All strain analysis on HFpEF patients and normal controls were performed by a single investigator.

Intra-observer variability for LA strain was assessed in 20 randomly selected PARAMOUNT studies which included 12 (60\%) of participants with LA enlargement $\left(\mathrm{LAVi}>29 \mathrm{ml} / \mathrm{m}^{2}\right)$. The overall coefficient of variation was $6.3 \%$ and intraclass correlation coefficient was 0.86 (95\% CI 0.75-0.98) for LA strain. Among HFpEF patients, we did not observe a significant difference in mean LA strain from apical 4-chamber and 2-chamber views (LA strain from apical 4-chamber: $24.6 \% \pm 8.1$ vs LA strain from apical 2-chamber: $23.6 \% \pm 7.7, \mathrm{p}=0.23)$.

\section{Statistical analysis}

All normally distributed data were presented as mean and standard deviation (continuous data) or as count and proportion (categorical data). Since NT-proBNP distribution was skewed, it was displayed as median and interquartile range and was log- transformed for analysis. Comparisons between groups were assessed using two- sample $t$ test with unequal variance or ANOVA (followed by Bonferroni correction) and $\chi^{2}$ test. After univariate screening, multivariable linear regression models were used to adjust systolic LA strain for selected clinically and statistically significant covariates (age, gender, heart rate, systolic blood pressure, body mass index, left atrial volume index (LAVi), LV global longitudinal strain, LV end-diastolic volume, LV stroke work, E/A, E'and E/E').

Additionally, we categorized the HFpEF patients according to quartiles of systolic LA strain, and applied trend tests across ordered groups to assess the association between LA dysfunction and demographic characteristics and echocardiographic measures of cardiac structure and function. All statistical analyses were performed with STATA 12.0 (Stata Corp, College Station, Texas). All tests were two-sided and p-values of $<0.05$ were considered statistically significant.

\section{Results}

\section{Clinical characteristics}

Patients with HFpEF were elderly, more frequently Caucasian (81\%), female and overweight. Most (92\%) had arterial hypertension, but blood pressure was well controlled (Table 1). All patients were using diuretics (inclusion criteria) and the majority of those patients were using ACE inhibitor or ARB (93\%) and b-blocker (81\%). As compared to the 
excluded HFpEF patients, the HFpEF patients included in this analysis had higher systolic blood pressure $(139 \pm 15 \mathrm{mmHg}$ vs $133 \pm 14 \mathrm{mmHg}, \mathrm{p}<0.001)$, slightly higher LV ejection fraction $(59 \pm 7 \%$ vs. $57 \pm 8 \%, \mathrm{p}=0.04)$ and filling pressure (E/E': $13.7 \pm 8.6$ vs $11.7 \pm 6.0$, $\mathrm{p}=0.04)$. Also, fewer of the patients included had a history of $\mathrm{AF}(23 \%$ vs $56 \%, \mathrm{p}<0.001)$, they had a lower heart rate $(66 \pm 13$ vs $72 \pm 12,<0.001)$, and smaller LAVi $(33.4 \pm 11.5$ vs $38.1 \pm 14.8, \mathrm{p}=0.004)$ than patients not included, likely due to the exclusion of patients with $\mathrm{AF}$ at the time of echocardiography.

Compared to controls, patients with HFpEF had similar LVEF, but lower LV global longitudinal strain. HFpEF patients also had higher LV and LA volumes; lower mitral annular relaxation velocities (E' and A') and higher E/E' compared to controls, who presented diastolic function parameters consistent with their age. ${ }^{22,23}$ There was no difference in LV mass between groups, even after adjusting for height ${ }^{2.7}$. The relative wall thickness was higher in controls than in HFpEF patients, which was driven by larger LV end diastolic diameter in the HFpEF group (Table 1). The elevated NT-proBNP, as inclusion criteria in the PARAMOUNT trial, can favor patients with larger left ventricles. Indeed, in our study, LV end diastolic diameter was significantly associated with NT- proBNP levels $(\mathrm{p}=0.04)$.

\section{LA function}

LA reservoir (systolic LA strain and LA emptying fraction), LA conduit (LA passive strain rate), and LA pump (LA active strain rate and LA active emptying fraction) function were significantly lower in HFpEF patients than in controls. (Figure 2) Also, LA expansion index (another measurement of LA reservoir function) was significantly lower in our HFpEF patients than in controls (114.4 \pm 7.6 in HFpEF versus $158.8 \pm 11.1$ in controls, $\mathrm{p}=0.002)$. The difference in LA reservoir function (measured by systolic LA strain) between groups remained significant even after adjustment for age, gender, heart rate, systolic blood pressure, BMI, LAVi, LV global longitudinal strain, LV end-diastolic volume, LV stroke volume, E/A ratio, E' and E/E' (p<0.001) (Table 2). As compared to controls, LA strain was lower even in the subset of HFpEF patients with normal LAVi $(\mathrm{n}=52)\left(\Omega 2 \mathrm{ml} / \mathrm{m}^{2}\right)^{16}$ (Figure 3 ) and in the subset of HFpEF patients without known history of AF (n=103) (Figure 4).

Among patients with HFpEF ( $\mathrm{n}=135)$, those with lower systolic LA strain had a higher prevalence of prior heart failure hospitalization, and history of AF, as well as worse LV systolic function (measured by LVEF and LV global longitudinal strain), higher LV mass and LAVi, when compared to patients with higher LA strain. However, NTproBNP levels and E/E' were similar across the quartiles of LA function (Table 3).

\section{Discussion}

We found that HFpEF patients had lower LA reservoir, conduit, and pump function than healthy controls. LA reservoir function (measured by systolic LA strain) remained significantly lower in the HFpEF group, even after adjustment for potential confounders, despite normal LA size and among those without a known history of AF. In HFpEF patients, lower systolic LA strain was associated with higher prevalence of prior heart failure hospitalization and history of AF, as well as lower LV systolic function, higher LV mass and 
LAVi. These findings suggest that LA dysfunction is prevalent in HFpEF and may contribute to its pathophysiology.

LA dysfunction has previously been described in HFpEF patients. ${ }^{14,24,25}$ In previous 2D speckle tracking studies, lower LA reservoir and pump function were demonstrated in HFpEF patients as compared with healthy controls ${ }^{26}$ or with asymptomatic patients with diastolic dysfunction. ${ }^{13}$ Strain analysis using speckle tracking is a direct measurement of intrinsic LA myocardial deformation, relatively independent of loading conditions and geometric assumptions ${ }^{27,28}$ and with high feasibility and reproducibility.19 Our results in a relatively large well-defined HFpEF group corroborate these prior studies and extend the findings of LA dysfunction to all 3 phases of LA function that may reflect an advanced stage of this syndrome. Further, we found that LA strain was the more robust measure of LA dysfunction in HFpEF patients in that it remained significantly different from controls even after multivariable adjustments and in the subsets with normal LA volume or without prior AF. These findings suggest that LA dysfunction may occur in HFpEF patients independent of LA dilation or remodeling caused by AF. However, due to the cross-sectional nature of this study we cannot conclusively discern whether early LA dysfunction is a consequence of HFpEF, or if LA dysfunction is a mechanism that contributes to an increased susceptibility to $\mathrm{HFpEF}$.

We also found that lower systolic LA strain was associated with a higher prevalence of prior heart failure hospitalization and history of AF. Previous studies showed that impaired LA function was a predictor of HF hospitalization in patients with HF with reduced ejection fraction ${ }^{29}$ and among patients with coronary disease and preserved ejection fraction. ${ }^{30}$ Moreover, LA dysfunction has been described in AF patients, ${ }^{31}$ which may be attributable to LA wall fibrosis ${ }^{32}$ and may also contribute to increased incidence of AF in HFpEF patients. ${ }^{4}$ We also observed that lower systolic LA strain was related to worse LV systolic function, greater LV hypertrophy (LVH) and LA structural remodeling. Impaired LV longitudinal strain has been associated with worse systolic LA strain due to the influence of downward motion of the mitral plane in the diastolic phase of LA. ${ }^{33-35}$ LVH may also contribute to LA dysfunction through pressure overload and increased LA wall tension; and worse LA strain has been shown to differentiate pathological from physiologic LVH. ${ }^{36,37}$ Thus, these pathophysiological mechanisms may play a pathophysiologic role in LA dysfunction associated with HFpEF. Higher LV filling pressures may lead to deterioration of LA function as a result of hemodynamic overload and mechanical stretch of the LA wall. ${ }^{38,39} \mathrm{We}$ did not find an independent association between E/E' or NT-proBNP with LA strain in our HFpEF group, which may be secondary to the fact that all patients enrolled in PARAMOUNT were required to have an elevated NT-proBNP.

Several limitations of our analysis should be noted. We analyzed a subset of the patients enrolled in the PARAMOUNT trial due to technical and quality requirements for LA speckle tracking analysis and high prevalence of AF at time of echocardiography, with some notable differences between the included and excluded patients. Although the analyses of threedimensional images may be a more accurate measurement, the protocol of PARAMOUNT trial required only two-dimensional images. ${ }^{40}$ Also, invasive methods to measure LV filling pressure were not available. In addition, the generalizability of these findings to HFpEF 
patients in the community may be limited because of the inclusion/exclusion criteria of the overall PARAMOUNT trial.

In summary, LA dysfunction was present among HFpEF patients and impaired LA reservoir function occurred regardless of LA size or history of AF. In HFpEF patients, lower systolic LA strain was associated with higher prevalence of prior heart failure hospitalization and history of AF, as well as worse LV systolic function, LV hypertrophy and LA remodeling, suggesting that LA dysfunction may be a marker of severity in HFpEF and may further play a pathophysiologic role in HFpEF. The additional clinical and prognostic relevance of LA function in HFpEF remains to be determined.

\section{Acknowledgments}

Dr Angela B. S. Santos acknowledges grant support (0281-12-3) from CAPES (Brazil).

Funding sources: The PARAMOUNT trial was sponsored by Novartis.

\section{References}

1. Owan TE, Hodge DO, Herges RM, Jacobsen SJ, Roger VL, Redfield MM. Trends in prevalence and outcome of heart failure with preserved ejection fraction. N Engl J Med. 2006; 355:251-259. [PubMed: 16855265]

2. Bhatia RS, Tu JV, Lee DS, Austin PC, Fang J, Haouzi A, Gong Y, Liu PP. Outcome of heart failure with preserved ejection fraction in a population-based study. N Engl J Med. 2006; 355:260-269. [PubMed: 16855266]

3. Meta-analysis Global Group in Chronic Heart Failure (MAGGIC). The survival of patients with heart failure with preserved or reduced left ventricular ejection fraction: an individual patient data meta-analysis. Eur Heart J. 2012; 33:1750-1757. [PubMed: 21821849]

4. Zakeri R, Chamberlain AM, Roger VL, Redfield MM. Temporal Relationship and Prognostic Significance of Atrial Fibrillation in Heart Failure Patients with Preserved Ejection Fraction: A Community-Based Study. Circulation. 2013; 128:1085-1093. [PubMed: 23908348]

5. Tsutsui H, Tsuchihashi M, Takeshita A. Mortality and readmission of hospitalized patients with congestive heart failure and preserved versus depressed systolic function. Am J Cardiol. 2001; 88:530-533. [PubMed: 11524063]

6. Fonarow GC, Stough WG, Abraham WT, Albert NM, Gheorghiade M, Greenberg BH, O'Connor CM, Sun JL, Yancy CW, Young JB. OPTIMIZE-HF Investigators and Hospitals. Characteristics, treatments, and outcomes of patients with preserved systolic function hospitalized for heart failure: a report from the OPTIMIZE-HF Registry. J Am Coll Cardiol. 2007; 50:768-777. [PubMed: 17707182]

7. Zile MR, Baicu CF, Gaasch WH. Diastolic heart failure--abnormalities in active relaxation and passive stiffness of the left ventricle. N Engl J Med. 2004; 350:1953-1959. [PubMed: 15128895]

8. Borlaug BA, Paulus WJ. Heart failure with preserved ejection fraction: pathophysiology, diagnosis, and treatment. Eur Heart J. 2011; 32:670-679. [PubMed: 21138935]

9. Pritchett AM, Mahoney DW, Jacobsen SJ, Rodeheffer RJ, Karon BL, Redfield MM. Diastolic dysfunction and left atrial volume: a population-based study. J Am Coll Cardiol. 2005; 45:87-92. [PubMed: 15629380]

10. Tsang TS, Barned ME, Gersh BJ, Bailey KR, Seward JB. Left atrial volume as a morphophysiologic expression of left ventricular diastolic dysfunction and relation to cardiovascular risk burden. Am J Cardiol. 2002; 90:1284-1289. [PubMed: 12480035]

11. Zile MR, Gottdiener JS, Hetzel SJ, McMurray JJ, Komajda M, McKelvie R, Baicu CF, Massie BM, Carson PE. I-PRESERVE Investigators. Prevalence and significance of alterations in cardiac structure and function in patients with heart failure and a preserved ejection fraction. Circulation. 2011; 124:2491-501. [PubMed: 22064591] 
12. Persson H, Lonn E, Edner M, Baruch L, Lang CC, Morton JJ, Ostergren J, McKelvie RS. Investigators of the CHARM Echocardiographic Substudy-CHARMES. Diastolic dysfunction in heart failure with preserved systolic function: need for objective evidence: results from the CHARM Echocardiographic Substudy-CHARMES. J Am Coll Cardiol. 2007; 49:687-694. [PubMed: 17291934]

13. Morris DA, Gailani M, Vaz Pérez A, Blaschke F, Dietz R, Haverkamp W, Ozcelik C. Left atrial systolic and diastolic dysfunction in heart failure with normal left ventricular ejection fraction. $\mathrm{J}$ Am Soc Echocardiogr. 2011; 24:651-662. [PubMed: 21458230]

14. Melenovsky V, Borlaug BA, Rosen B, Hay I, Ferruci L, Morell CH, Lakatta EG, Najjar SS, Kass DA. Cardiovascular features of heart failure with preserved ejection fraction versus nonfailing hypertensive left ventricular hypertrophy in the urban Baltimore community: the role of atrial remodeling/dysfunction. J Am Coll Cardiol. 2007; 49:198-207. [PubMed: 17222731]

15. Solomon SD, Zile M, Pieske B, Voors A, Shah A, Kraigher-Krainer E, Shi V, Bransford T, Takeuchi M, Gong J, Lefkowitz M, Packer M, McMurray JJ. Prospective comparison of ARNI with ARB on Management Of heart failUre with preserved ejectioN fracTion (PARAMOUNT) Investigators. The angiotensin receptor neprilysin inhibitor LCZ696 in heart failure with preserved ejection fraction: a phase 2 double-blind randomised controlled trial. Lancet. 2012; 380:13871395. [PubMed: 22932717]

16. Lang RM, Bierig M, Devereux RB, Flachskampf FA, Foster E, Pellikka PA, Picard MH, Roman MJ, Seward J, Shanewise JS, Solomon SD, Spencer KT, Sutton MS, Stewart WJ. Chamber Quantification Writing Group; American Society of Echocardiography's Guidelines and Standards Committee; European Association of Echocardiography. Recommendations for chamber quantification: a report from the American Society of Echocardiography's Guidelines and Standards Committee and the Chamber Quantification Writing Group, developed in conjunction with the European Association of Echocardiography, a branch of the European Society of Cardiology. J Am Soc Echocardiogr. 2005; 18:1440-63. [PubMed: 16376782]

17. Nagueh SF, Appleton CP, Gillebert TC, Marino PN, Oh JK, Smiseth OA, Waggoner AD, Flachskampf FA, Pellikka PA, Evangelisa A. Recommendations for the evaluation of left ventricular diastolic function by echocardiography. Eur J Echocardiogr. 2009; 10:165-93.

18. de Simone G, Chinali M, Galderisi M, Benincasa M, Girfoglio D, Botta I, D'Addeo G, de Divitiis O. Myocardial mechano-energetic efficiency in hypertensive adults. J Hypertens. 2009; 27:650-5. [PubMed: 19330923]

19. Cameli M, Caputo M, Mondillo S, Ballo P, Palmerini E, Lisi M, Marino E, Galderisi M. Feasibility and reference values of left atrial longitudinal strain imaging by two-dimensional speckle tracking. Cardiovasc Ultrasound. 2009; 87:6.

20. Perk G, Tunick PA, Kronzon I. Non-Doppler two-dimensional strain imaging by echocardiography--from technical considerations to clinical applications. J Am Soc Echocardiogr. 2007; 20:234-243. [PubMed: 17336748]

21. Kraigher-Krainer E, Shah AM, Gupta DK, Santos A, Claggett B, Pieske B, Zile MR, Voors AA, Lefkowitz MP, Packer M, McMurray JJ, Solomon SD. PARAMOUNT Investigators. Impaired Systolic Function by Strain Imaging in Heart Failure with Preserved Ejection Fraction. J Am Coll Cardiol. 2014; 63:447-56. [PubMed: 24184245]

22. Klein AL, Burstow DJ, Tajik AJ, Bailey KR, Seward JB. Effects of age on left ventricular dimensions and filling dynamics in 117 normal persons. Mayo Clin Proc. 1994; 69:212-24. [PubMed: 8133658]

23. De Sutter J, De Backer J, Van de Veire N, Velghe A, De Buyzere M, Gillebert Zachariah PKTC. Effects of age, gender, and left ventricular mass on septal mitral annulus velocity ( $\left.E^{\prime}\right)$ and the ratio of transmitral early peak velocity to E' (E/E'). Am J Cardiol. 2005; 95:1020-3. [PubMed: 15820183]

24. Gottdiener JS, Kitzman DW, Aurigemma GP, Arnold AM, Manolio TA. Left atrial volume, geometry, and function in systolic and diastolic heart failure of persons $>$ or $=65$ years of age (the cardiovascular health study). Am J Cardiol. 2006; 97:83-89. [PubMed: 16377289]

25. Tan YT, Wenzelburger F, Lee E, Nightingale P, Heatlie G, Leyva F, Sanderson JE. Reduced left atrial function on exercise in patients with heart failure and normal ejection fraction. Heart. 2010; 96:1017-1023. [PubMed: 20584857] 
26. Kurt M, Wang J, Torre-Amione G, Nagueh SF. Left atrial function in diastolic heart failure. Circ Cardiovasc Imaging. 2009; 2:10-15. [PubMed: 19808559]

27. Boyd AC, Richards DA, Marwick T, Thomas L. Atrial strain rate is a sensitive measure of alterations in atrial phasic function in healthy ageing. Heart. 2011; 97:1513-1519. [PubMed: 21749989]

28. Zhang Q, Yip GW, Yu CM. Approaching regional left atrial function by tissue Doppler velocity and strain imaging. Europace. 2008; 10:62-69.

29. Motoki H, Borowski AG, Shrestha K, Troughton RW, Martin MG, Tang WH, Klein AL. Impact of Left Ventricular Diastolic Function on Left Atrial Mechanics in Systolic Heart Failure. Am J Cardiol. 2013; 112:821-826. [PubMed: 23764244]

30. Welles CC, Ku IA, Kwan DM, Whooley MA, Schiller NB, Turakhia MP. Left atrial function predicts heart failure hospitalization in subjects with preserved ejection fraction and coronary heart disease: longitudinal data from the Heart and Soul Study. J Am Coll Cardiol. 2012; 59:673-680. [PubMed: 22322084]

31. Kojima T, Kawasaki M, Tanaka R, Ono K, Hirose T, Iwama M, Watanabe T, Noda T, Watanabe S, Takemura G, Minatoguchi S. Left atrial global and regional function in patients with paroxysmal atrial fibrillation has already been impaired before enlargement of left atrium: velocity vector imaging echocardiography study. Eur Heart J Cardiovasc Imaging. 2012; 13:227-234. [PubMed: 22166594]

32. Kuppahally SS, Akoum N, Burgon NS, Badger TJ, Kholmovski EG, Vijayakumar S, Rao SN, Blauer J, Fish EN, Dibella EV, Macleod RS, McGann C, Litwin SE, Marrouche NF. Left atrial strain and strain rate in patients with paroxysmal and persistent atrial fibrillation: relationship to left atrial structural remodeling detected by delayed-enhancement MRI. Circ Cardiovasc Imaging. 2010; 3:231-9. [PubMed: 20133512]

33. Barbier P, Solomon SB, Schiller NB, Glantz SA. Left atrial relaxation and left ventricular systolic function determine left atrial reservoir function. Circulation. 1999; 100:427-436. [PubMed: 10421605]

34. Ersbøll M1, Andersen MJ, Valeur N, Mogensen UM, Waziri H, Møller JE, Hassager C, Søgaard P, Køber L. The prognostic value of left atrial peak reservoir strain in acute myocardial infarction is dependent on left ventricular longitudinal function and left atrial size. Circ Cardiovasc Imaging. 2013; 6:26-33. [PubMed: 23192848]

35. Russo C, Jin Z, Homma S, Rundek T, Elkind MS, Sacco RL, Di Tullio MR. Left atrial minimum volume and reservoir function as correlates of left ventricular diastolic function: impact of left ventricular systolic function. Heart. 2012; 98:813-820. [PubMed: 22543839]

36. D'Andrea A, De Corato G, Scarafile R, Romano S, Reigler L, Mita C, Allocca F, Limongelli G, Gigantino G, Liccardo B, Cuomo S, Tagliamonte G, Caso P, Calbrò R. Left atrial myocardial function in either physiological or pathological left ventricular hypertrophy: a two-dimensional speckle strain study. Br J Sports Med. 2008; 42:696-702. [PubMed: 18070810]

37. Gabrielli L, Enríquez A, Córdova S, Yáñez F, Godoy I, Corbalán R. Assessment of left atrial function in hypertrophic cardiomyopathy and athlete's heart: a left atrial myocardial deformation study. Echocardiography. 2012; 29:943-949. [PubMed: 22954405]

38. Guan Z, Zhang D, Huang R, Zhang F, Wang Q, Guo S. Association of left atrial myocardial function with left ventricular diastolic dysfunction in subjects with preserved systolic function: a strain rate imaging study. Clin Cardiol. 2010; 33:643-649. [PubMed: 20960540]

39. Prioli A, Marino P, Lanzoni L, Zardini P. Increasing degrees of left ventricular filling impairment modulate left atrial function in humans. Am J Cardiol. 1998; 82:756-61. [PubMed: 9761086]

40. Nagaya M, Kawasaki M, Tanaka R, Onishi N, Sato N, Ono K, Watanabe T, Minatoguchi S, Miwa H, Goto Y, Hirose T, Arai M, Noda T, Watanabe S, Minatoguchi S. Quantitative validation of left atrial structure and function by two-dimensional and three-dimensional speckle tracking echocardiography: a comparative study with three-dimensional computed tomography. J Cardiol. 2013; 62:188-94. [PubMed: 23672788] 

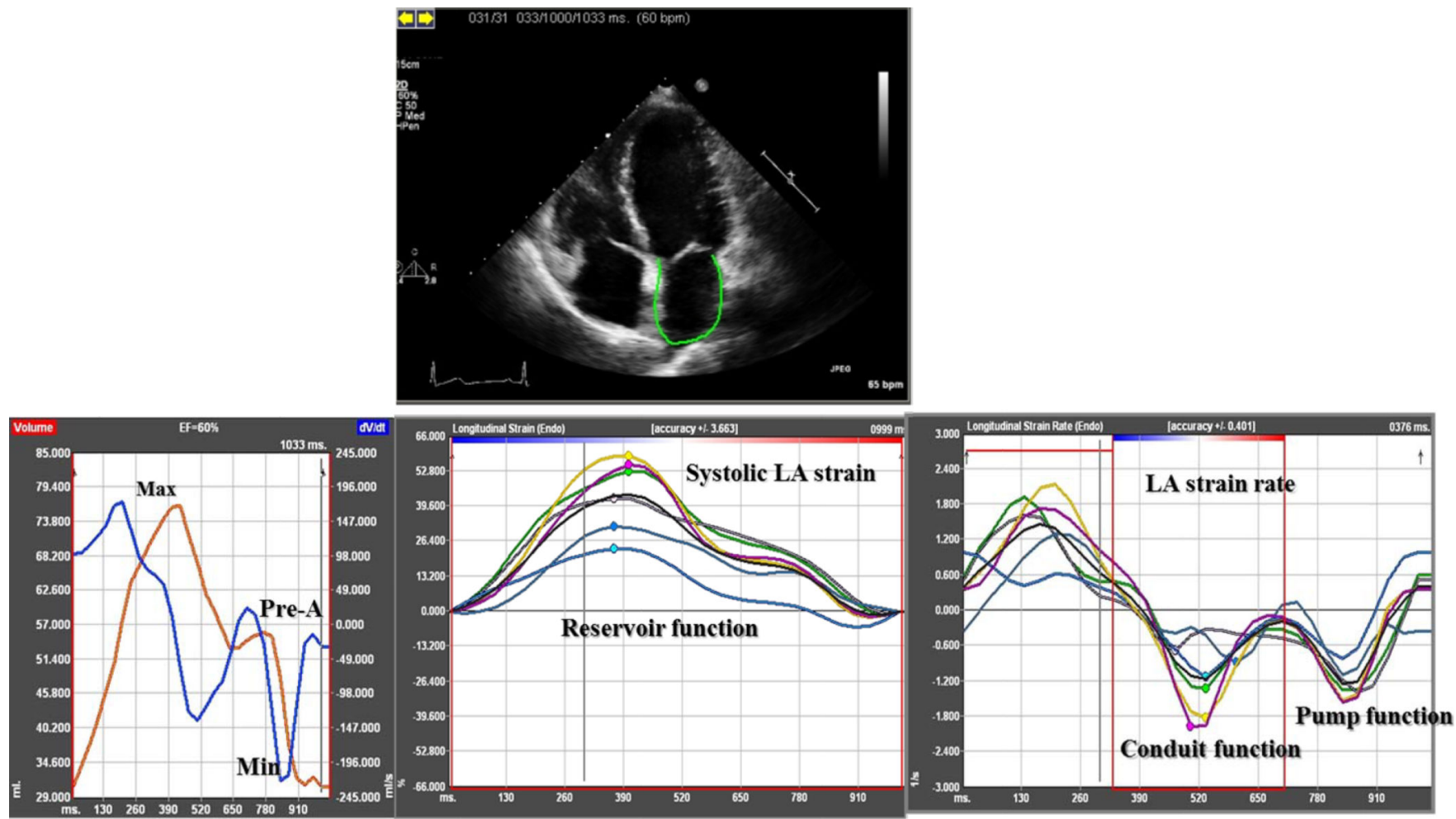

Figure 1.

Two-dimensional speckle tracking imaging in the apical four-chamber view in a healthy patient.

Legend: Left panel presents left atrial (LA) phasic volumes (orange curve); middle panel presents LA reservoir function measured by strain, and right panel presents LA conduit function (first negative peak) and LA pump function (second negative peak) assessed by strain rate. 


\section{LA Reservoir Function}

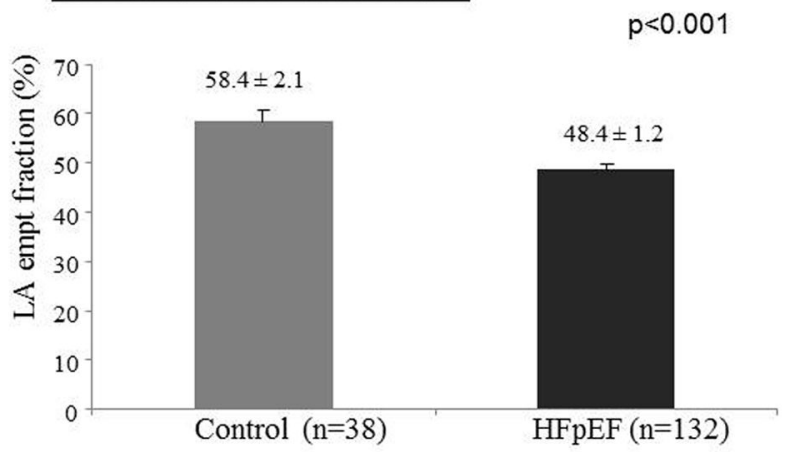

\section{$\underline{\text { LA Conduit Function }}$}

$p=0.09$
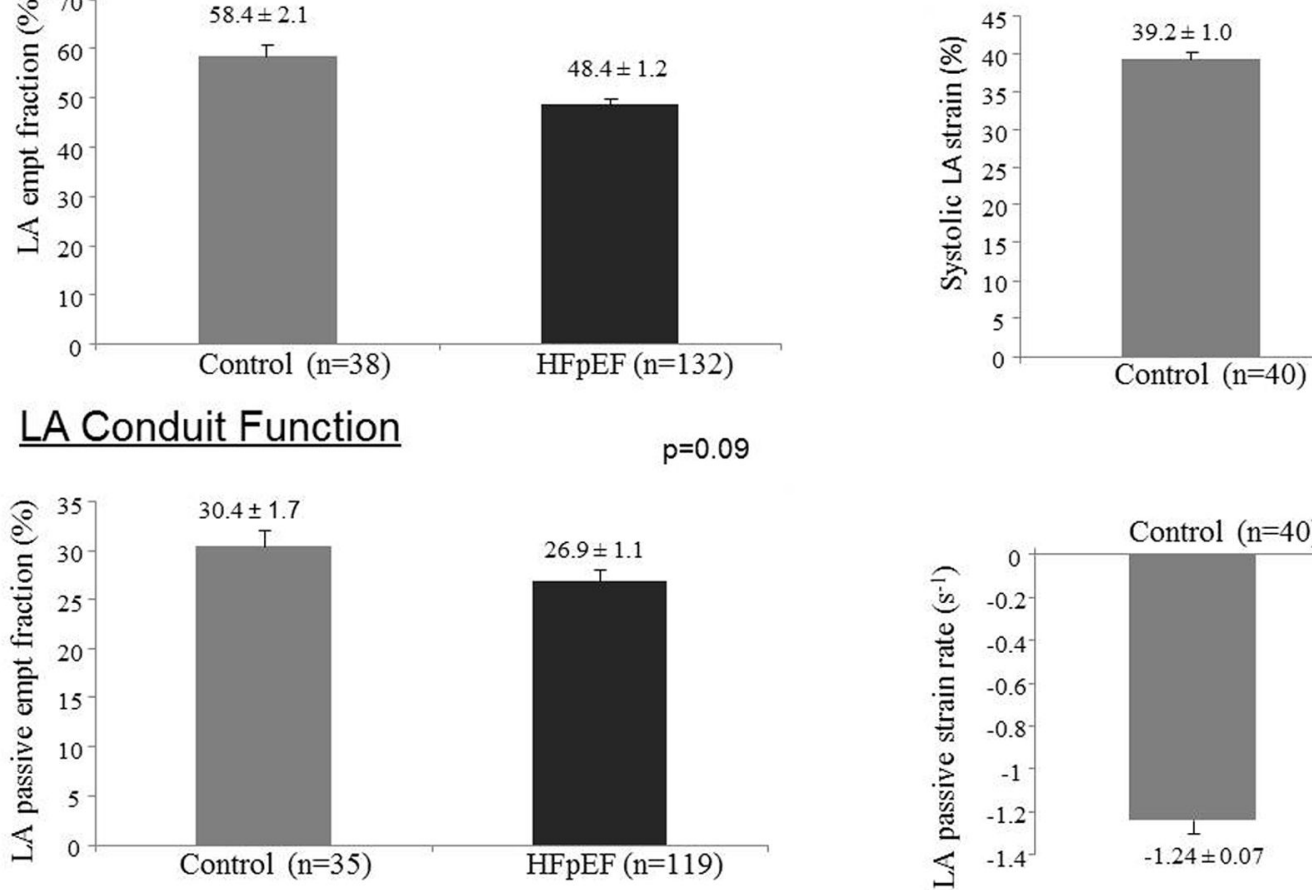

$p<0.001$

\section{LA Pump Function}
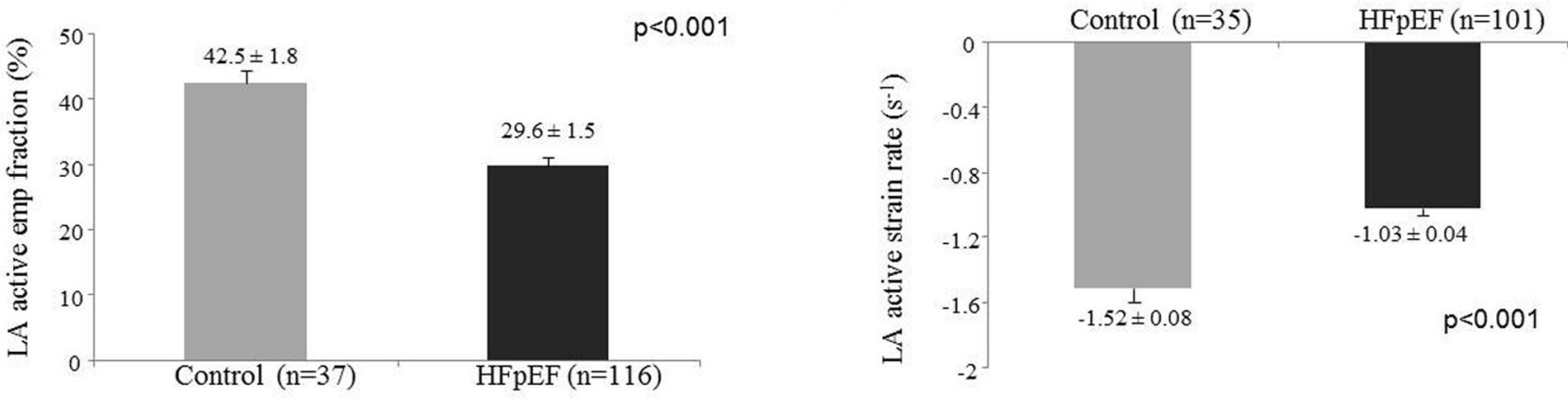

Figure 2.

Comparison of left atrial function (reservoir, conduit and pump function) between healthy controls (gray bar) and HFpEF patients (black bar)

Legend: Data are shown as mean $\pm \mathrm{SE}$ $\mathrm{LA}=$ left atrial. 


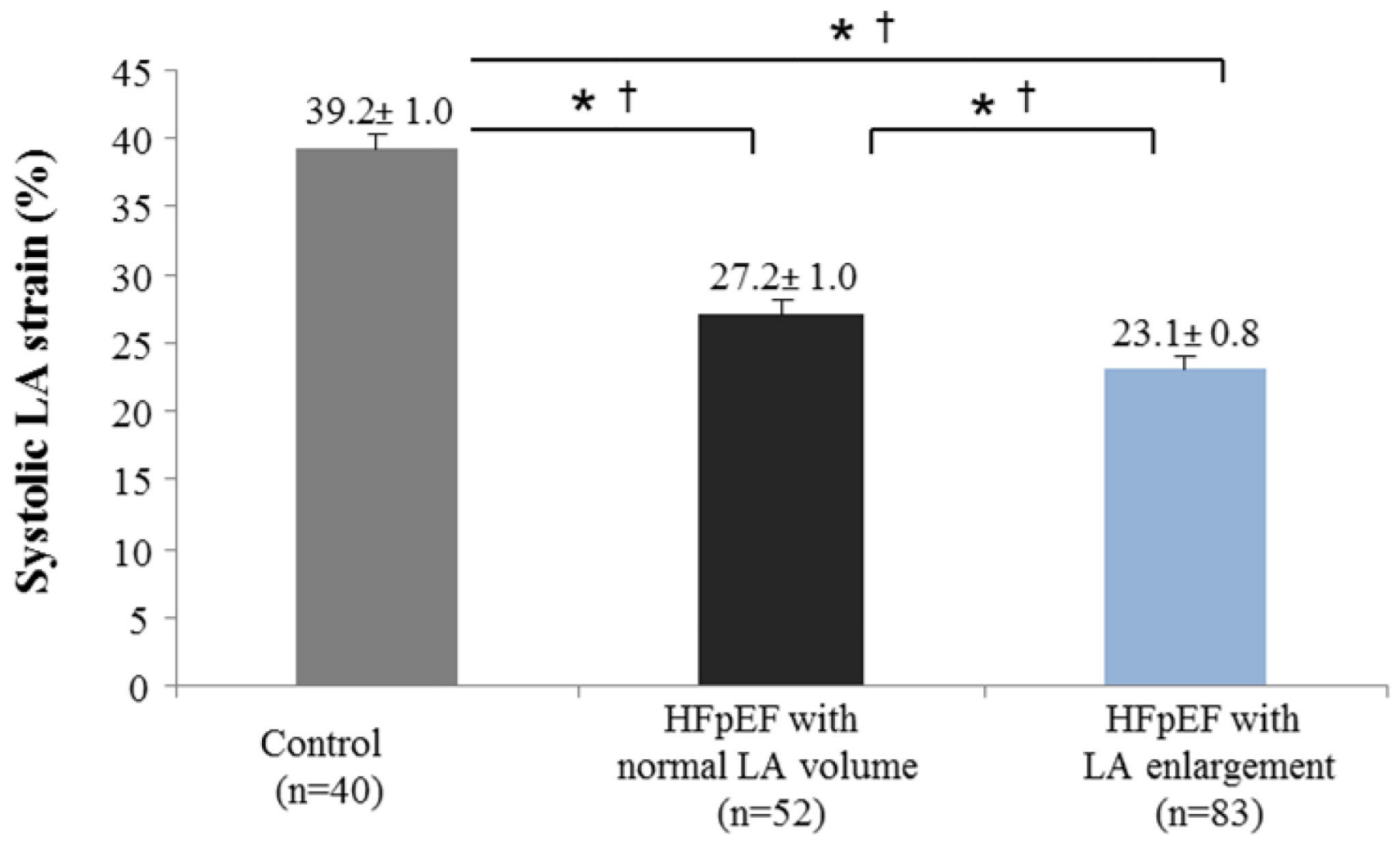

Figure 3.

Comparison of left atrial (LA) reservoir function (measured by systolic LA strain) among healthy controls, and HFpEF patients with normal LA volume ( $\Omega 9 \mathrm{ml} / \mathrm{m}^{2}$ ) and with LA enlargement $\left(>29 \mathrm{ml} / \mathrm{m}^{2}\right.$ )

Legend: Data are shown as mean \pm SE.

*unadjusted $\mathrm{p}$ value $(<0.01)$.

$\dagger p$ value $(<0.01)$ adjusted for age, gender, heart rate, systolic blood pressure, body mass index, LV global longitudinal strain and E/E'. 


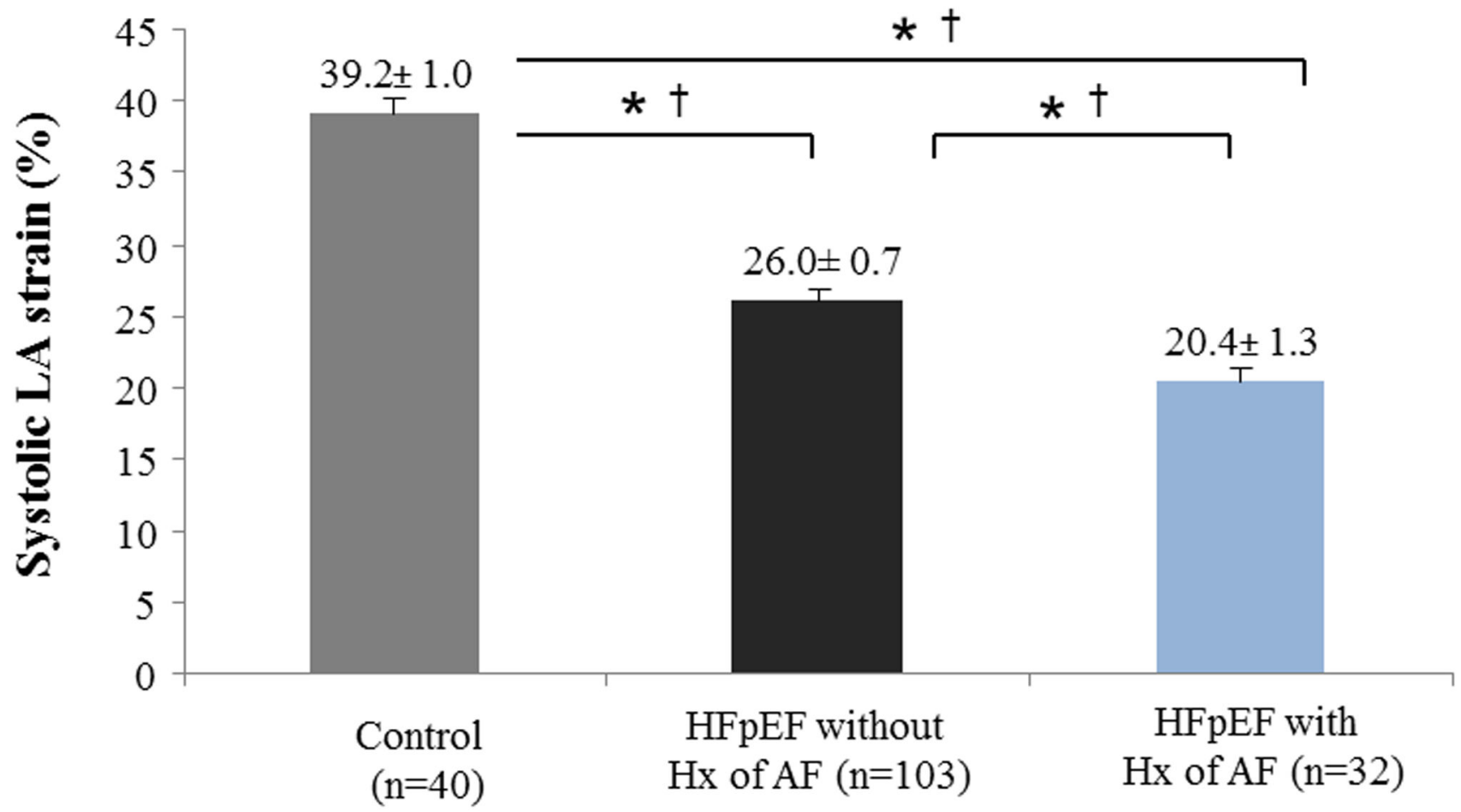

Figure 4.

Comparison of LA reservoir function (measured by systolic LA strain) among healthy controls, and HFpEF patients without and with known history of atrial fibrillation (AF) Legend: Data are shown as mean \pm SE.

*unadjusted $\mathrm{p}$ value $(<0.001)$.

$\dagger p$ value $(<0.01)$ adjusted for age, gender, heart rate, systolic blood pressure, body mass index, LV global longitudinal strain and E/E'. 


\section{Table 1}

Baseline characteristics of the study population

\begin{tabular}{|c|c|c|c|}
\hline & $\underset{(n=40)}{\text { Controls }}$ & $\begin{array}{l}\text { HFpEF } \\
(\mathbf{n}=135)\end{array}$ & p value \\
\hline Age (years) & $68 \pm 6$ & $70 \pm 9$ & 0.051 \\
\hline Women, n (\%) & $27(68)$ & $83(61)$ & 0.49 \\
\hline NYHA II, n (\%) & -- & $108(81)$ & \\
\hline NYHA III, n (\%) & -- & $26(19)$ & \\
\hline Previous Hospitalization for HF, n (\%) & $0(0)$ & $66(50)$ & \\
\hline History of Atrial Fibrillation, $\mathrm{n}(\%)$ & $0(0)$ & $31(23)$ & \\
\hline History of Hypertension, $\mathrm{n}(\%)$ & $0(0)$ & $123(92)$ & \\
\hline History of Diabetes, n (\%) & $0(0)$ & $47(35)$ & \\
\hline History of Myocardial Infarction, $\mathrm{n}(\%)$ & $0(0)$ & $30(22)$ & \\
\hline Heart Rate (beats per min) & $71 \pm 14$ & $66 \pm 13$ & 0.04 \\
\hline Systolic Blood Pressure (mm Hg) & $127 \pm 15$ & $139 \pm 16$ & $<0.001$ \\
\hline Diastolic Blood Pressure (mm Hg) & $74 \pm 11$ & $78 \pm 11$ & 0.04 \\
\hline Body Mass Index $\left(\mathrm{kg} / \mathrm{m}^{2}\right)$ & $25.2 \pm 3.7$ & $29.6 \pm 5.7$ & $<0.001$ \\
\hline NT-proBNP (pg/mL) & -- & $809[446,1300]$ & \\
\hline \multicolumn{4}{|l|}{ Baseline treatments } \\
\hline ACE inhibitors or ARBs, $\mathrm{n}(\%)$ & $0(0)$ & $125(93)$ & \\
\hline Diuretic, n (\%) & $0(0)$ & $135(100)$ & \\
\hline B Blockers, n (\%) & $0(0)$ & $109(81)$ & \\
\hline Aldosterone Antagonists, n (\%) & $0(0)$ & $24(18)$ & \\
\hline \multicolumn{4}{|l|}{ Echocardiographic measures } \\
\hline LV Ejection Fraction (\%) & $60 \pm 3$ & $59 \pm 7$ & 0.22 \\
\hline Global Longitudinal Strain (\%) & $-19.9 \pm 2.2$ & $-15.0 \pm 3.4$ & $<0.001$ \\
\hline LV End-Diastolic Volume (mL) & $85.2 \pm 24.5$ & $114.1 \pm 28.1$ & $<0.001$ \\
\hline LV End-Diastolic Volume /BSA $\left(\mathrm{mL} / \mathrm{m}^{2}\right)$ & $48.4 \pm 11.0$ & $61.8 \pm 14.3$ & $<0.001$ \\
\hline LV End-Systolic Volume (mL) & $34.9 \pm 13.6$ & $47.3 \pm 16.4$ & $<0.001$ \\
\hline LV End-Systolic Volume/BSA $\left(\mathrm{mL} / \mathrm{m}^{2}\right)$ & $19.6 \pm 6.5$ & $25.5 \pm 8.5$ & $<0.001$ \\
\hline Relative Wall Thickness & $0.42 \pm 0.07$ & $0.38 \pm 0.09$ & 0.004 \\
\hline LV Mass Index ( $\left.\mathrm{g} / \mathrm{m}^{2}\right)$ & $77.5 \pm 17.0$ & $79.4 \pm 21.8$ & 0.57 \\
\hline LV Mass/height ${ }^{2.7}\left(\mathrm{~g} / \mathrm{m}^{2.7}\right)$ & $35.7 \pm 7.6$ & $38.5 \pm 11.3$ & 0.09 \\
\hline LV stroke work (g-m) & $92.4 \pm 21.8$ & $130.3 \pm 37.4$ & $<0.001$ \\
\hline$E^{\prime}(\mathrm{cm} / \mathrm{s})$ & $9.4 \pm 2.1$ & $6.6 \pm 2.4$ & $<0.001$ \\
\hline$A^{\prime}(\mathrm{cm} / \mathrm{s})$ & $10.8 \pm 2.8$ & $7.2 \pm 2.5$ & $<0.001$ \\
\hline $\mathrm{E} / \mathrm{E}^{\prime}$ & $7.5 \pm 2.5$ & $13.7 \pm 8.6$ & $<0.001$ \\
\hline $\mathrm{E}(\mathrm{cm} / \mathrm{s})$ & $66.7 \pm 15.6$ & $78.0 \pm 27.7$ & 0.002 \\
\hline $\mathrm{A}(\mathrm{cm} / \mathrm{s})$ & $72.2 \pm 18.0$ & $74.0 \pm 27.6$ & 0.63 \\
\hline $\mathrm{E} / \mathrm{A}$ & $0.95 \pm 0.23$ & $1.20 \pm 0.67$ & $<0.001$ \\
\hline Deceleration time (ms) & $203.8 \pm 41.0$ & $214.3 \pm 39.0$ & 0.18 \\
\hline Left Atrial Volume Index $\left(\mathrm{mL} / \mathrm{m}^{2}\right)$ & $21.1 \pm 5.3$ & $33.4 \pm 11.5$ & $<0.001$ \\
\hline
\end{tabular}

Eur J Heart Fail. Author manuscript; available in PMC 2017 July 31. 
Data are presented as $\mathrm{n}(\%)$ and mean $\pm \mathrm{SD}$.

$\mathrm{p}$ values was calculated by ttest or $X^{2}$

$\mathrm{NYHA}=$ New York Heart Association. ACE $=$ angiotensin-converting enzyme .

$\mathrm{ARB}=$ angiotensin receptor blocker. $\mathrm{E}$ '= early lateral mitral relaxation velocity. $\mathrm{A}^{\prime}=$ late lateral mitral relaxation velocity. $\mathrm{E} / \mathrm{E}$ '=mitral inflow to mitral relaxation velocity ratio. $\mathrm{E} / \mathrm{A}=$ early to late mitral inflow velocity ratio. $\mathrm{E}=$ early mitral inflow velocity. $\mathrm{A}=$ late mitral inflow velocity. $\mathrm{LA}=$ Left Atrial. 
Table 2

\begin{tabular}{|c|c|c|c|c|c|}
\hline \multirow{2}{*}{$\frac{\unrhd}{\stackrel{D}{\vec{D}}}$} & \multicolumn{5}{|l|}{ Predictors of systolic LA strain } \\
\hline & & \multicolumn{2}{|c|}{ Unadjusted } & \multicolumn{2}{|c|}{ Adjusted $^{*}$} \\
\hline$z$ & & B & $\mathbf{p}$ & B & $\mathbf{p}$ \\
\hline ֻి & $\mathrm{HFpEF}$ & -14.6 & $<0.001$ & -8.41 & $<0.001$ \\
\hline $\bar{c}$ & Age (years) & -0.21 & 0.013 & -0.15 & 0.02 \\
\hline O․ & Male & 0.31 & 0.837 & -1.8 & 0.12 \\
\hline$\overline{\mathbf{C}}$ & Heart Rate & 0.12 & 0.022 & 0.05 & 0.23 \\
\hline & Systolic Blood Pressure (mm Hg) & -0.09 & 0.039 & -0.05 & 0.25 \\
\hline & Body Mass Index $\left(\mathrm{kg} / \mathrm{m}^{2}\right)$ & -0.37 & 0.002 & -0.11 & 0.35 \\
\hline & Global Longitudinal Strain (\%) & -1.35 & $<0.001$ & -0.7 & $<0.001$ \\
\hline & LV End-Diastolic Volume /BSA (mL/m²) & -0.11 & 0.021 & -0.01 & 0.92 \\
\hline & LV stroke work (g-m) & -0.03 & 0.168 & 0.08 & 0.01 \\
\hline$\sum$ & $\mathrm{E} / \mathrm{E}$ & -0.037 & $<0.001$ & -0.06 & 0.47 \\
\hline $\bar{c}$ & $E^{\prime}(\mathrm{cm} / \mathrm{s})$ & 1.02 & $<0.001$ & -0.08 & 0.79 \\
\hline $\bar{z}$ & $\mathrm{E} / \mathrm{A}$ & -5.35 & $<0.001$ & -2.7 & 0.01 \\
\hline $\overrightarrow{\underline{N}}$ & Left Atrial Volume Index $\left(\mathrm{mL} / \mathrm{m}^{2}\right)$ & -0.41 & $<0.001$ & -0.2 & 0.001 \\
\hline
\end{tabular}




\section{을 \\ 골}

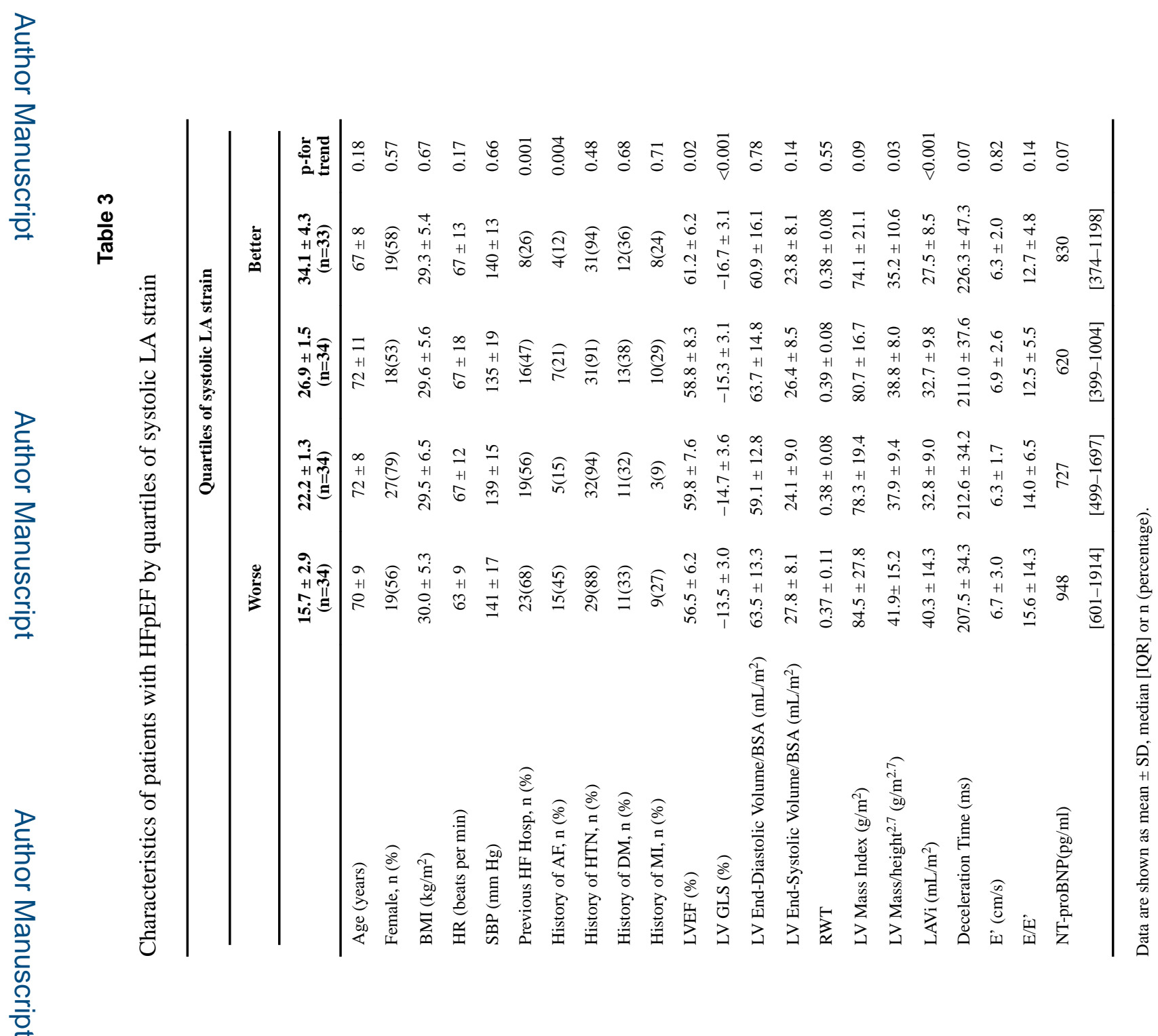

Eur J Heart Fail. Author manuscript; available in PMC 2017 July 31. 


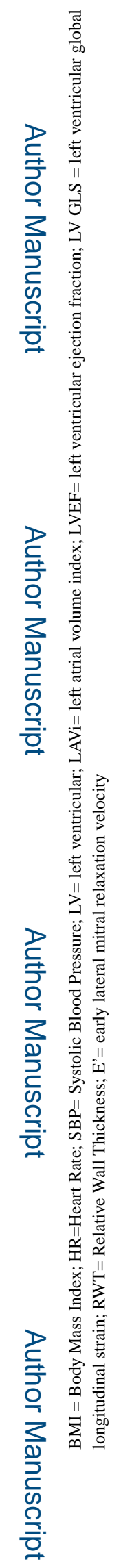

Eur J Heart Fail. Author manuscript; available in PMC 2017 July 31. 